furnace slags. The lines in Johnson's X-ray patterns (private communication), which he considers to be due to a new phase, seem to accord with the strongest lines found in the pattern reported here. The stable phase assemblages between the new compound and adjoining compounds are being studied. It is already clear, however, that over a wide range of composition between $2 \mathrm{CaO}, \mathrm{SiO}_{2}$ and $3 \mathrm{CaO}, \mathrm{MgO}, 2 \mathrm{SiO}_{2}$ the X-ray pattern of the new phase is unaltered, supporting the view that the phase is a singular compound and not a member of a solid-solution series.

$$
\text { W. GuTT }
$$

Building Research Station,

(Department of Scientific and Industrial Research), Garston,
Watford.

1 Welch, J. H., J. Sci. Instr., 31, 458 (1954).

2 Welch, J. H., and Gutt, W., J. Amer. Ceramic Soc., 42, 11 (1959).

'A Aruja, E., Welch, J. H., and Gutt, W., J. Sci. Instr., 36, 16 (1959).

4 Sharp, J. D., Johnson, W., and Andrews, K. W., J. Iron and Stee Inst., 195,, 83 (1960).

\section{Use of Krypton for Surface Area}

We have recently discussed ${ }^{1}$ some criteria for the applicability of various gases in measuring the surface areas of solids by the Brunauer-EmmettTeller ${ }^{2}$ method. We concluded that the use of krypton in this technique led to valid and useful results and that previous criticism of the use of this gas was unfounded. However, Thomas ${ }^{3}$ has again suggested that 'anomalous' Brunauer-Emmett-Teller plots obtained from krypton adsorption measurements render the use of this gas undesirable. He proposes that the occurrence of phase-changes in the adsorbed film, evidenced by discontinuities in the adsorption isotherm, are associated with these 'anomalous' (and presumably suspect) results.

We wish to re-emphasize the fact that an evaluation of monolayer coverage must be based on the behaviour of the adsorbed film when the first monolayer is nearly complete. Two-dimensional condensation or other transitions in the adsorbed. film at lower or higher coverages do not appear to affect the validity of the surface areas evaluated from linear BrunauerEmmett-Teller plots in the monolayer region. McDermot and Lawton 4 , for example, were able to evaluate the surface area of a graphite sample from krypton-adsorption data even though they observed two discontinuities in the isotherm at $77^{\circ} \mathrm{K}$. The work of Roberts ${ }^{5}$ strongly suggests that krypton adsorbed on an evaporated iron film can be considered a two-dimensional liquid at coverages greater than about 80 per cent of the first monolayer. The energetic considerations which we have previously used $^{1}$ are therefore applicable, and valid surface area measurements are obtained in these cases.

We submit, therefore, that the non-linear parts of the plots described by Thomas are irrelevant to the purposes of surface area measurement. The application of the self-consistency criterion ${ }^{1,6}$ :

$$
p / p_{0} \mid v_{m}=\frac{1}{1+\sqrt{ } c}
$$

suggests, however, that if his measurements had been carried to somewhat higher pressures, Thomas would have obtained valid $v_{m}$ values.
It must be remembered that the useful linear range of a Brunauer-Emmett-Teller plot varies, in terms of relative pressure, with the nature of the solid surface, as we have already shown'.

\section{Peter Cannon \\ George L. Gaines, Jun.}

General Electric Research Laboratory, Schenectady, New York.

1 Gaines, jun., G. L., and Cannon, P., J. Phys. Chem., 64, 997 (1960). 2 Brunauer, S., Emmett, P. H., and Teller, E., J. Amer. Chem. Soc., 60,309 (i938).

3 Thomas, J. M., Nature, 189, 134 (1961).

4 McDermot, H. L., and Lawton, B. F., Canad. J. Chem., 37, 54 (1959).

${ }^{5}$ Roberts, M. W., Trans, Farad. Soc., 56, 128 (1960).

- Meyer, L., Z. phys. Chemie, N.F., 16, 331 (1958).

\section{Properties of Polyadenylic Acid in Methanol Solution}

UNTIL recent years, methanol and ethanol were universally regarded only as precipitants for nucleic acids. However, Geiduschek and Holtzer', and later Coates and Jordan ${ }^{2}$, showed that at sufficiently low ionic strengths both the above lose their precipitating capacity for deoxyribonucleic acid (DNA) and in fact becomes fairly good solvents, depending upon the concentration of electrolyte.

The above authors have also observed a profound alteration of the over-all macromolecular properties of DNA in the above media, including a drastic fall in intrinsic viscosity and rise in frictional coefficient without any important change in molecular weight. The extensive molecular collapse indicated by the above was largely reversed on replacement of alcohol by dialysis versus water, suggesting that irreversible 'denaturation' in the classical sense had not occurred in this instance.

The present investigation deals with the properties of polyriboadenylic acid (poly A) dissolved in anhydrous methanol. Such criteria as ultra-violet hypochromism and optical rotation have been interpreted as indicating that the alkaline form of poly $A$ in aqueous solution possesses varying degrees of helical content, depending on conditions, and displays in fact many of the characteristics of an intermittently helical system, being rather analogous to ribonucleic acid ${ }^{3,4}$.

Solutions of poly A (1 per cent) in water were dialysed exhaustively versus anhydrous methanol according to the procedure of Geiduschek ${ }^{\mathbf{1}}$. (The poly A used was prepared by the action of the polynucleotide phosphorylase of $M$. lysodeikticus (supplied by Dr. R. Beere) upon adenosine diphosphate.) After dialysis they were diluted five-fold with methanol. The final water content was less than 1 per cent. No dependence of molecular properties on water content was observed for values of the latter less than 5

\begin{tabular}{|c|c|c|}
\hline \multicolumn{3}{|c|}{ Table 1} \\
\hline Solvent & $\begin{array}{c}\text { Water } \\
(0 \cdot 001 M \\
\text { sodium acetate })\end{array}$ & $\begin{array}{c}\text { Methanol } \\
(0.001 M \\
\text { sodium acetate })\end{array}$ \\
\hline $\begin{array}{l}\text { Absorbancy } \\
\left(\lambda=260 \mathrm{~m} \mu\left(20^{\circ} \mathrm{C} .\right)\right)\end{array}$ & 9,500 & 13,600 \\
\hline $\begin{array}{l}\text { Absorbancy } \\
\left(\lambda=260 \mathrm{~m} \mu\left(50^{\circ} \mathrm{C} .\right)\right) \\
\text { Sedimentation }\end{array}$ & 12,400 & 13,600 \\
\hline coefficient $\left(S_{*, \infty}^{20} \times 10^{18}\right)$ & 6.9 & 50 \\
\hline $\begin{array}{l}\text { Intrinsic viscosity } \\
\text { Optical rotation }\left([a]_{d}\right)\end{array}$ & $\begin{array}{r}16 \cdot 8 \\
+100^{\circ}\end{array}$ & $\begin{array}{l}\stackrel{0 \cdot 26}{-25} \\
-25\end{array}$ \\
\hline
\end{tabular}
per cent.

* Corrected for thermal expansion of solvent. 